\title{
Endosonography-guided alteration of upper surgical anatomy to facilitate endoscopic management of biliary cast syndrome post-liver transplantation
}

A 41-year-old woman who had undergone orthotopic liver transplantation (OLT) with Roux-en-Y reconstruction for primary sclerosing cholangitis (PSC) presented with recurrent cholangitis due to biliary cast syndrome. She had undergone a total of seven enteroscopy-assisted endoscopic retrograde cholangiopancreatographies (ERCPs) at an outside tertiary institution without successful clinical results. She was referred to our center for further management. Magnetic resonance cholangiopancreatogra- phy (MRCP) revealed an extensive burden of large intrahepatic stones ( $>$ Fig. 1 a). Recently, endoscopic ultrasonography (EUS)-guided creation of a gastroenteric anastomosis has been described using a lumen-apposing metal stent (LAMS) for the management of benign and malignant gastric outlet obstruction [1,2]. Creation of such an anastomosis may be beneficial in patients with complex surgical upper gastrointestinal anatomy who present with challenging pancreaticobiliary pathologies. The plan was to create an endoscopic gastrojejunostomy fistula using a LAMS close to the hepaticojejunostomy to permit subsequent endoscopic management of biliary cast syndrome with conventional ERCP and electrohydraulic lithotripsy (EHL).

The afferent limb was accessed with an enteroscope and was filled with a mixed solution of saline, contrast, and methylene blue. The limb was easily localized with EUS transgastrically and was then punctured with a $19 \mathrm{G}$ needle, with aspiration of blue dye confirming it was
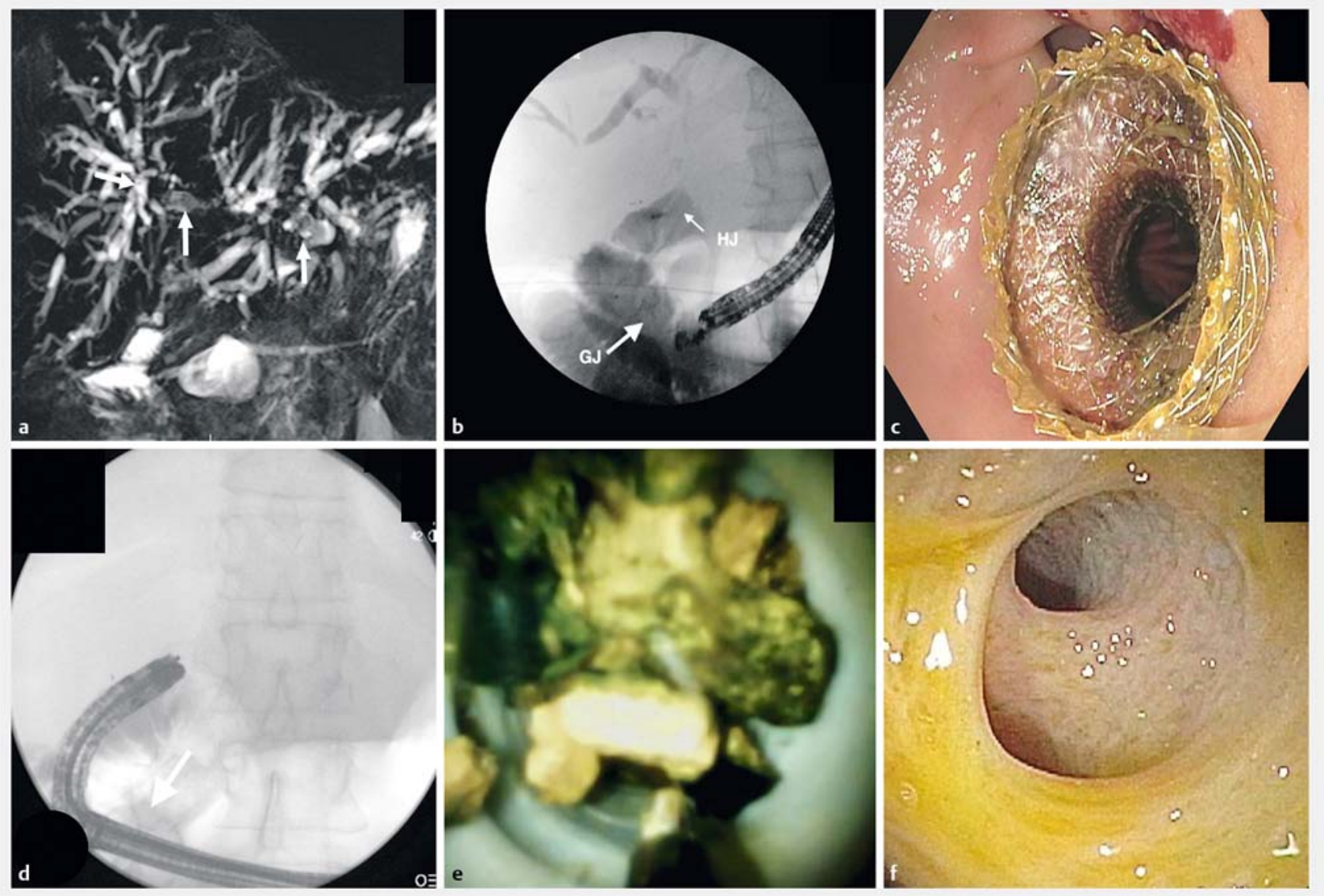

- Fig. 1 Management of biliary cast syndrome in a patient who had undergone liver transplantation with Roux-en-Y reconstruction. a Magnetic resonance cholangiopancreatography image showing multiple large intrahepatic stones (arrows). b Fluoroscopic view of the gastrojejunostomy (G]; large arrow) near the hepaticojejunostomy (HJ; small arrow). c Endoscopic view of a deployed gastrojejunostomy lumen-apposing metal stent (LAMS). $\mathbf{d}$ Fluoroscopic view of an endoscope passing through the LAMS (arrow). e Cholangioscopy-guided electrohydraulic lithotripsy $(\mathrm{EHL})$ with the tip of the catheter targeting a large intrahepatic stone. $\mathrm{f}$ Cholangioscopy view 8 weeks after EHL therapy of the stones showing complete right intrahepatic duct clearance. 


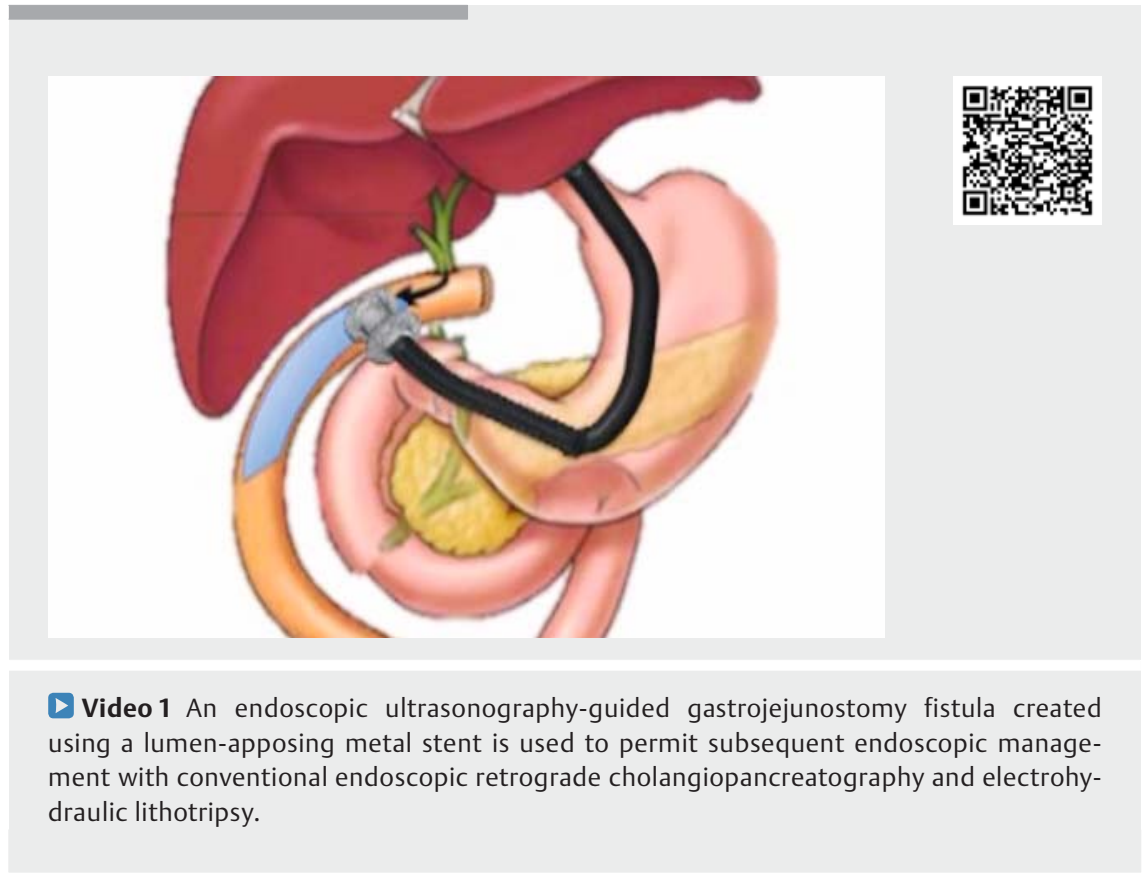

correctly placed. An EUS-guided gastrojejunostomy was created using the direct technique and a 15-mm LAMS with electrocautery-enhanced delivery system (Axios; Boston Scientific Massachusetts, USA) ( $\triangleright$ Fig. 1 b, c).

A further ERCP was performed 4 weeks later, during which a standard therapeutic gastroscope was advanced through the fistula and the stent into the hepa-

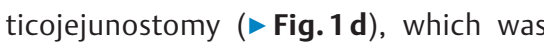
few centimeters distal to the created endoscopic gastrojejunostomy. A cholangiogram revealed dilated intrahepatic ducts with multiple small and large filling defects consistent with intrahepatic stones. The digital single-operator cholangioscope (Spyglass DS; Boston Scientific) was advanced over the guidewire into the intrahepatic ducts. Multiple large stones were seen in the intrahepatic ducts. An EHL probe was introduced through the working channel of the cholangioscope, with the tip positioned directly at the stone ( $\mathbf{F i g .} \mathbf{1}$ e). The stones were fragmented into small pieces. The digital cholangioscope was advanced into secondary and tertiary branches of the right intrahepatic duct under fluoroscopic and cholangioscopic guidance. The right intrahepatic system was packed with large stones. Large stones throughout the intrahepatic system were successfully fragmented into small pieces to ensure passage through the small ducts. A plastic biliary stent $(7 \mathrm{Fr} \times 9 \mathrm{~cm})$ was placed into the left intrahepatic duct and a fully covered self-expandable metallic stent $(8 \mathrm{~mm} \times 60 \mathrm{~mm}$; WallFlex, Boston Scientific) was placed in the right intrahepatic duct to facilitate passage of the fragmented stones ( $\vee$ Video 1 ).

The patient developed mild post-procedural cholangitis, which was successfully treated conservatively with antibiotics. An ERCP was performed again 8 weeks later. Contrast injection and cholangioscopy confirmed no evidence of residual stones ( $\mathbf{F i g} \mathbf{1} \mathbf{f}$ ).

EUS-guided alteration of complex surgical anatomy with the creation of an endoscopic gastrojejunostomy is feasible and allows easy access to the bilio-enteric anastomosis. This permits the use of standard ERCP equipment and, thus, performance of intricate biliary interventions and management of challenging biliary pathologies, such as biliary cast syndrome and difficult biliary stones.

Endoscopy_UCTN_Code_TTT_1AR_2AK
Competing interests

Mouen A. Khashab is a consultant and on the medical advisory board for Boston Scientific and Olympus and is a consultant for Medtronic. The remaining authors have nothing to disclose.

The authors

Majidah A. Bukhari, ${ }^{1,2}$, Olaya Brewer ${ }^{1}$, Yen-I Chen ${ }^{1}$, Saowanee Ngamruengphong ${ }^{1}$, Omid Sanaei ${ }^{1}$, Payal Saxena ${ }^{3}$, Mouen A. Khashab ${ }^{1}$

1 Division of Gastroenterology, Johns Hopkins Hospital, Baltimore, Maryland, USA

2 Division of Medicine and Gastroenterology and Hepatology, International Medical City in Jeddah, Saudi Arabia

3 Gastroenterologist and Interventional Endoscopist, Royal Prince Alfred Hospital, Missenden Rd, Camperdown, Sydney, Australia

Corresponding author

Mouen A. Khashab, MD

Division of Gastroenterology and

Hepatology, Johns Hopkins Hospital, 1800

Orleans Street, Zayed Bldg, Suite 7125B,

Baltimore, MD 21287, USA

Fax: +1-443-683-8335

mkhasha1@jhmi.edu

\section{References}

[1] Khashab MA, Kumbhari V, Grimm IS et al. EUS-guided gastroenterostomy: the first U.S. clinical experience (with video). Gastrointest Endosc 2015; 82: 932 - 938

[2] Khashab MA, Tieu AH, Azola A et al. EUSguided gastrojejunostomy for management of complete gastric outlet obstruction. Gastrointest Endosc 2015; 82: 745

\section{Bibliography}

DOI https://doi.org/10.1055/a-0929-3529

Published online: 1.7.2019

Endoscopy 2019; 51: E374-E375

(c) Georg Thieme Verlag KG

Stuttgart · New York

ISSN 0013-726X 